\title{
Assessment of the sustainability of wild rocket (Diplotaxis tenuifolia) production: Application of a multi-criteria method to different farming systems in the province of Udine
}

\author{
Stefania Troiano, Veronica Novelli, Paola Geatti*, Francesco Marangon, Luciano Ceccon \\ Department of Economics and Statistics, University of Udine, Via Tomadini 30/A, 33100 Udine, Italy
}

\section{A R T I C L E I N F O}

\section{Keywords:}

Wild rocket

Multi-attribute value theory

Conventional agriculture

Organic agriculture

Biodynamic agriculture

Sustainable agriculture

\begin{abstract}
A B S T R A C T
Evaluating the economic, social and environmental impacts of different cultivation systems is an essential issue for the introduction of management practices that aim at both achieving more sustainable forms of land use and improving social well-being. A number of studies compared and assessed organic and conventional farms in relation to their multifunctional effects. However, to our knowledge there is no literature which took into account at the same time the multifunctional role of a greater number of different farming methods. In this paper an attempt is made to employ the multi-criteria method in order to conduct quantitative assessment of the degree of multi-functionality on three different farming methods, namely, conventional, organic and biodynamic. A species of leaf vegetable was considered, that is, wild rocket. The three farms taken into examination are all located in the province of Udine, Italy, with a maximum distance of about $20 \mathrm{~km}$ one from another. In all the three farms, greenhouses equipped with the same type of roofing were employed. The research was carried on for two consecutive years, that is, 2012 and 2013; spring, summer and autumn productions were considered. In this way we minimized the influence of some parameters (climatic conditions, luminosity, growing period), but the specific techniques adopted in the three farms were not optimized. The producers continued to utilize the methods usually employed in their farms, in order to obtain results showing the productive situation of the territory. The obtained information was used as input data for the multi-attribute model. Attributes and utility functions were organized under three major groups: economic, social and environmental parameters. Findings may be regarded simply as the results of a pilot study, as they were obtained on a small sample of farms, but suggest that the degree of multi-functionality is the most explicit in the case of the biodynamic farm, that has a better property and social structure.
\end{abstract}

\section{Introduction}

Agriculture, in particular intensive agriculture, has been able to cover the increasing food demand, but at the same time is responsible of environmental damages to marine, freshwater and Earth ecosystems caused mainly by fertilizer and pesticide use (Tilman et al., 2011). Nevertheless, beyond its primary function, agriculture can also provide a broad array of valuable services (e.g., maintenance of landscape, soil conservation, sustainable management of renewable environmental resources, preservation of biodiversity, contribution to the socio-economic development of many rural areas) (Power, 2010), according to its multifunctional role. The approach of sustainable agriculture involves the transition from the use of synthetic to natural substances, with the implication of the human and social capital: agricultural knowledge, management attitudes and the ability to work together
(Pretty, 2003). Agricultural sustainability, measured by economic, social and environmental indicators, is at the base of the farm performances (Dantsis et al., 2010). Because of its holistic and multidimensional nature, agricultural sustainability needs specific assessment methods.

Over the past years, various methods have been developed for making sustainability assessments (Jeswani et al., 2010; Zahm et al., 2008; Zhang and Haapala, 2015), which prove to be useful in supporting decision-makers simultaneously and smartly to evaluate the economic, social and environmental dimensions of sustainability also of different cropping/farming systems (Binder et al., 2010; Bockstaller et al., 2009; Carof et al., 2013; Gerbens-Leenes et al., 2003). Evaluating sustainability is a typical multi-criteria assessment problem (DiazBalteiro et al., 2017; Janeiro and Patel 2015; Munda, 2012; Roy and Słowiński, 2013). Multi-criteria decision-making methods (MCDM) help

\footnotetext{
* Corresponding author.

E-mail address: paola.geatti@uniud.it (P. Geatti).
} 
decision-makers in taking decisions for complex issues or situations such as sustainability (Cegan et al., 2017; Huang et al., 2011), not having to work under quantitative and long-term grounds (Vučijak et al., 2015). MCDM looks for negotiated solutions among conflicting criteria and indicators (Munda, 2005). It should be noted that the way in which the decision is reached is influenced by the underlying paradigm of sustainable development (weak or strong sustainability approaches) held by the decision-makers (Janeiro and Patel, 2015). Although the strong sustainability theory seems to be suitable for this target, the practical implementation of this concept is far from trivial (Janeiro and Patel, 2015). It is easy to think about situations in which institutional makers would trade off environmental sustainability in order to enhance other social and economic aspirations (Kurth et al., 2017). Moreover, any method trying to put into operation the concept of sustainability can be treated as a "second best", since the term "sustainability" is characterized by an inherent complexity (Munda, 2012). Nevertheless, it is important to try to determine an understanding of the environmental principle of sustainability and a way of making it operational by employing defined criteria and indicators, in order to be able to make judgements as to whether socio-economic systems are moving towards environmental sustainability or not. Furthermore, Andreoli and Tellarini (2000), Sadok et al. (2009) and Fagioli et al. (2017) stated that the use of a MCDM approach can be useful to evaluate farm performance taking into account all the relevant impacts of different farming systems, and to address their practices toward sustainability.

Multi-attribute utility theory (MAUT) is a methodological subgroup of MCDM, and is used in cases of discrete and limited numbers of alternatives that are characterized by a number of antagonistic criteria (Hwang and Yoon, 1981; Werner et al., 2014). According to this method, alternative options are compared for their different social, economic and environmental impacts, and ranked depending on a set of chosen criteria (Hermann et al., 2007). Agricultural sustainability can be evaluated by the application of a multi-attribute analysis (Dyer, 2016; Hwang and Yoon, 1981) in order to compare different (economic, social and environmental) performances of different farming systems (Kylili et al., 2016; Saaty and Ergu, 2015). MAUT may be a solid approach for the implementation of agricultural management practices aimed at achieving sustainable forms of land use and, more in general, to enhance social well-being (Castellini et al., 2012; Hayashi, 2000; Meyer-Aurich, 2005). In addition, it allows to identify the most environmentally friendly agronomic techniques. Moreover, MAUT can be based on different sets of axioms suitable for use in different circumstances (Dyer, 2016). The aim of MAUT is to find a manageable expression for the decision-makers' preferences (Zavadskas et al., 2010) in order to determine and modify the impacts of their activities. Multiattribute value theory (MAVT) is a simplification of MAUT, as it does not try to model the decision makers' attitude to risk. Yatsalo et al. (2007) stated that, when describing applied MCDM problems, in a number of cases, authors do not distinguish MAUT and MAVT, as they simply indicate the implementation of MAUT/MAVT methods.

There are numerous examples of applications of MCDM in agriculture and related fields (Cardín-Pedrosa and Alvarez-López, 2012; Gómez-Limón et al., 2004; Hayashi, 2000; Marangon and Tempesta, 1998; Montazar and Snyder, 2012; Parra-López et al., 2007; Piech and Rehman, 1993; Riesgo and Gomez-Limon, 2006; Sadok et al., 2008). According to Ramírez-García et al. (2015), Rehman and Romero (1993) reviewed the application of MCDM techniques to the management of agricultural systems; since then, MCDM techniques have been applied to a wide range of topics such as the evaluation of the sustainability of different agricultural managements (Sadok et al., 2008; Würtenberger et al., 2006) or the farm production planning (Ortuño and Vitoriano, 2011). The review of the literature reveals that a number of studies compared and evaluated organic and conventional farms in relation to their multifunctional impacts (Parra-López et al., 2008; Parra-López et al., 2007; Rozman et al., 2006; Sadok et al., 2008; Van Calker et al.,
2006). However, to our knowledge there is no literature which investigated and compared at the same time the multifunctional role of a greater number of different farming methods.

Therefore, the goal of this study was to apply the MAVT methodology to evaluate the economic, social and environmental impact of different cultivation systems of wild rocket, with the aim of providing an easy instrument to help stakeholders (in particular farmers and institutions) in decision-making processes while choosing which growing techniques to adopt, in the case of farmers, or promote, in the case of institutions, in a particular geographic area.

\section{Materials and methods}

We implemented the five basic steps to develop an assessment by a MAVT model (Zeleny, 1982). We trained the decision-makers in the terminology, concepts and methods to be used; in addition, we tested the corresponding independence conditions to justify the appropriate functional form of the multi-attribute utility function. To test them, we interviewed the decision-makers by questionnaires created in order to assess each condition according to postulates of theory (Keeney and Raiffa, 1993). Then, we assessed the individual utility functions for each objective which was considered relevant to the decision problem; moreover, we estimated the weights associated with each utility function, and combined the individual utility functions into an aggregate utility function; last not least, we tested the consistency of the obtained findings. Consequently, the first step of this study was the characterisation of the problem of sustainable production management of wild rocket and the identification of all the relevant stakeholders involved. The identification of the main stakeholders involved was based on interviews with experts with local knowledge and the utilization of the snowball principle (Luyet et al., 2012). This principle involves asking already defined stakeholders to designate new ones. Five stakeholder groups were selected (i.e. regional administration, agricultural representatives, environmental organizations, farmers, regional rural development administration).

Although the precise meaning of sustainable agriculture is far from clear (Sadok et al., 2008), a number of objectives was defined after discussion and adaptation by experts and stakeholders to gain acceptance of the results. The general top-level objective (e.g. sustainability) was broken into increasingly specific operational objectives. The members of each group were asked to rate the objectives on a scale of $0-100$ according to the definition of objective proposed by Keeney (1992). Although all the objectives contribute to the overall target of sustainable production of wild rocket, the average was used to define an objective rating. Then results had been discussed during a focus group to reach a consensus among stakeholders. To evaluate this goal, we used data collected directly in the three farms.

\subsection{Data collection}

To meet our purposes, that is, to compare the multifunctional role of different farming methods, a possible experimental design could be to carry on the investigation over a wide territory (e.g., North-Eastern Italy or even Northern Italy) by involving a large number of farms. However, this choice would have required the introduction in the research of many heterogeneous variables (e.g., climatic conditions, soil characteristics and fertility, farm size) that would have made difficult both to compare the results obtained for the farms considered and to apply the results to all the territory taken into examination. One of the main purposes of the application of MAVT is to give useful indications to both farms and institutional decision-makers in order to promote and improve economic, social and environmental sustainability of the territory. Therefore, we preferred to restrict the investigation to a more limited area, that is, the Friuli Venezia Giulia region (North-Eastern Italy), to reduce to a minimum the variability associated to climatic conditions and soil characteristics and fertility. Furthermore, we 
decided to consider the production of a specific leaf vegetable, that is, wild rocket (Diplotaxis tenuifolia). Our interest towards rocket was due to the fact that in the two last decades rocket farming has expanded hugely (Cerny et al., 1996; Koukounaras et al., 2007; Nicoletti et al., 2007) because of several success factors: rocket is available at affordable prices throughout the year, its production can be carried out in a rather easy way, it is appreciated by a large number of consumers because of its intense aroma, it is characterized by a greater shelf life compared to other leaf vegetables. Furthermore, the use of rocket is increasing also for the great consumption of ready-to-use salads. In response to this rapidly growing demand for rocket, long-term sustainability concerns could emerge from intensive farming.

Nineteen farms that cultivated wild rocket had been registered in the Friuli Venezia Giulia region in 2011 (Cattivello, 2013), but the number of organic farms was very small, and, most notably, only one biodynamic and one hydroponic farms were present. However, the hydroponic farm was not available to participate in the research. Since the biodynamic farm was located in the province of Udine, we preferred to limit the research to this territory. In this way, it was possible to reduce to a minimum the variability associated also to farm size, as almost exclusively small farms were present in the province of Udine. For reasons of homogeneity, we limited the investigation to only one farm for each of the three types of production employed. The use of MAVT to assess explicitly and simultaneously the economic, social and environmental aspects of the sustainability of different farming methods, including the biodynamic one, to produce wild rocket has never been reported in the literature.

Wild rocket was cultivated for two consecutive years, that is, 2012 and 2013 , in three farms located in a limited area of the province of Udine, with a maximum distance of $20 \mathrm{~km}$ one from another. All farms carried out greenhouse methods of production. All greenhouses employed in the three farms had no heating system and were equipped with the same type of roofing (ethylene/ethyl vinyl acetate (EVA) copolymer with $14-18 \%$ of EVA). Data were collected relative to spring, summer and autumn production of both years considered. In this way we minimized the influence of some other parameters (luminosity, growing period), in order to have a more precise cognition of the effects of the cultivation techniques employed. Inside the greenhouses, luminosity was determined by utilizing a Sunfleck Ceptometer instrument (Decagon, Pullman, WA, USA). Before seeding, soils were tilled to a $30 \mathrm{~cm}$ depth in a comparable way in all cases, by mechanical ploughing in the conventional and organic farms, and by hand spading in the biodynamic farm.

Seeding densities and average yields for each of the three farms are reported in Table 1. These two parameters are of great importance for the purposes of our investigation, as they represent respectively one of the economic (yield) and one of the environmental (seeding density) indicators selected (see the following Section 2.2 and Table 3).

The technological features adopted by the three farms are shown in Table 2.

Table 1

Seeding densities and average yields of wild rocket relative to the two years of investigation.

Farming methods $/$ seeding densities and average yields

\begin{tabular}{lllll}
\hline & 2012 & & 2013 & \\
\hline & $\begin{array}{l}\text { Seeding density } \\
\left(\text { plants } / \mathrm{m}^{2}\right)\end{array}$ & $\begin{array}{l}\text { Yield } \\
\left(\mathrm{g} / \mathrm{m}^{2}\right)\end{array}$ & $\begin{array}{l}\text { Seeding density } \\
\left(\text { plants } / \mathrm{m}^{2}\right)\end{array}$ & $\begin{array}{l}\text { Yield } \\
\left(\mathrm{g} / \mathrm{m}^{2}\right)\end{array}$ \\
\hline C & 2764 & 530 & 3350 & 478 \\
B & 1928 & 696 & 2781 & 645 \\
O & 711 & 724 & 1487 & 855 \\
\hline
\end{tabular}

* $\mathrm{C}=$ conventional, $\mathrm{B}=$ biodynamic, $\mathrm{O}=$ organic.
Table 2

Technological features adopted by the three farms.

\begin{tabular}{|c|c|c|c|}
\hline $\begin{array}{l}\text { Technological } \\
\text { features }\end{array}$ & Conventional & Organic & Biodynamic $^{\mathrm{a}}$ \\
\hline Greenhouse area & $1100 \mathrm{~m}^{2}$ & $250 \mathrm{~m}^{2}$ & $80 \mathrm{~m}^{2}$ \\
\hline Manure employed & $\begin{array}{l}\text { NPK fertilizer } \\
\left(20 \mathrm{~kg} / 1000 \mathrm{~m}^{2}\right)^{\mathrm{b}}\end{array}$ & $\begin{array}{l}\text { Dried manure } \\
\left(1.20 \mathrm{~kg} / \mathrm{m}^{2}\right)^{\mathrm{b}}\end{array}$ & $\begin{array}{l}\text { Compost }(3 \mathrm{~kg} / \\
\left.\mathrm{m}^{2}\right)^{\mathrm{c}}\end{array}$ \\
\hline $\begin{array}{l}\text { Herbicides } \\
\text { employed }^{\mathrm{b}}\end{array}$ & $\begin{array}{l}\text { Benfluoralin }^{\mathrm{d}} \\
\text { Glyphosate }^{\mathrm{e}}\end{array}$ & & \\
\hline $\begin{array}{l}\text { Fungicides } \\
\text { employed }^{\mathrm{b}}\end{array}$ & Metalaxyl $^{\mathrm{d}}$ & & \\
\hline $\begin{array}{l}\text { Insecticides } \\
\text { employed }^{\mathrm{b}}\end{array}$ & & Azadiractine & \\
\hline $\begin{array}{l}\text { Seed amount } \\
\text { employed }\end{array}$ & $0.960 \mathrm{~g} / \mathrm{m}^{2}$ & $2.700 \mathrm{~g} / \mathrm{m}^{2}$ & $1.333 \mathrm{~g} / \mathrm{m}^{2}$ \\
\hline $\begin{array}{l}\text { System employed } \\
\text { for irrigation }\end{array}$ & Sprinkling system & Ground hoses & $\begin{array}{l}\text { Sprinkling } \\
\text { system }\end{array}$ \\
\hline $\begin{array}{l}\text { Water employed for } \\
\text { irrigation }^{\text {f }}\end{array}$ & $11,200 \mathrm{~L}$ & $2500 \mathrm{~L}$ & $5860 \mathrm{~L}$ \\
\hline $\begin{array}{l}\text { Number of reapings } \\
\text { collected }^{\mathrm{b}}\end{array}$ & 1 & 4 & 2 \\
\hline
\end{tabular}

a A preliminary treatment on the seeds by employing a homeopathic preparation obtained by meteoric iron and clay and a subsequent treatment on soils by employing another homeopathic preparation obtained by cow-horn manure and clay were carried out for each seeding. A homeopathic treatment on soils was carried out on May of both years by employing a third biodynamic preparation.

b For each production cycle.

c Only once in 2012.

d On the whole greenhouse area.

e On the external perimeter of the flower-beds.

f Average amount for each greenhouse and for each production cycle.

\subsection{Indicators}

To try to assess sustainability, we involved an extended peer community. Local stakeholders (including farmers), with knowledge of sustainability and wild rocket production systems, were contacted to identify applicable sustainability indicators and to assess their relative importance in the context of wild rocket production systems. All of the stakeholders were from the study area, since it was considered relevant to ensure that they were familiar with the local conditions of wild rocket production.

To develop the multi-criteria decision analysis, twenty-nine indicators were selected for different dimensions of sustainability (economic, social and environmental) (Table 3) in order to compare and classify the cultivation systems (alternatives). This number was considered to be sufficient to give a first picture of the socio-economic and environmental impacts of each production system.

The indicators were identified in similar but separate data collection processes. These processes were composed of two phases. In the former phase, 30 stakeholders were sent a list of possible sustainability indicators acquired from a previous literature review. They were asked to select from the list the indicators considered to be relevant when comparing the sustainability of the three systems of wild rocket production. Thus, they received a list including all the sustainability indicators chosen. The stakeholders were asked to rank the importance of the indicators on a scale of $0-100$ ( 0 being the less important one).

To evaluate economic indicators, all the production costs were calculated; however, twelve economic indicators were chosen to compare the three production systems in terms of financial viability or profitability (Table 3 ). These indicators can be considered long-established economic indicators used to develop MCDM in order to suggest a priority of choices among different agricultural production systems (Castellini et al., 2012).

The first and second economic indicators (wild rocket surface area; yield) represent the area devoted to and the density in wild rocket plantation, while self-consumption regards the quantity of wild rocket 
Table 3

Indicators selected for description of sustainability of farming methods (unit, mark and direction of preference).

\begin{tabular}{|c|c|c|c|c|c|c|c|}
\hline Indicator & Unit & Mark & Direction & Indicator & Unit & Mark & Direction \\
\hline \multicolumn{8}{|l|}{ Economic indicators } \\
\hline wild rocket surface area & $\mathrm{m}^{2}$ & E1 & $\max$ & gross saleable production & $€ / \mathrm{m}^{2}$ & E7 & $\max$ \\
\hline yield & $\mathrm{g} / \mathrm{m}^{2}$ & $\mathrm{E} 2$ & $\max$ & fertilizers and crop protection costs & $€ / \mathrm{m}^{2}$ & E8 & $\min$ \\
\hline self-consumption & $\mathrm{g} / \mathrm{m}^{2}$ & E3 & $\min$ & irrigation costs & $€ / \mathrm{m}^{2}$ & E9 & $\min$ \\
\hline wild rocket crop sales & $\mathrm{g} / \mathrm{m}^{2}$ & E4 & $\max$ & fuel costs & $€ / \mathrm{m}^{2}$ & E10 & $\min$ \\
\hline revenue & $€ / \mathrm{m}^{2}$ & E5 & $\max$ & certification costs & $€ / \mathrm{m}^{2}$ & E11 & $\min$ \\
\hline subsidies, government program payments & $€ / \mathrm{m}^{2}$ & E6 & $\max$ & labour costs & $€ / \mathrm{m}^{2}$ & E12 & $\min$ \\
\hline \multicolumn{8}{|l|}{ Social indicators } \\
\hline land tenure & $\%$ & $\mathrm{~S} 1$ & $\max$ & seasonal workers & number & S6 & $\min$ \\
\hline total farm area & ha & $\mathrm{S} 2$ & $\max$ & farmers' educational qualification & level & S7 & $\max$ \\
\hline plots of land & number & S3 & $\min$ & diversification & number & S8 & $\max$ \\
\hline organic area & $\%$ & S4 & $\max$ & primary products revenues & $\%$ & S9 & $\min$ \\
\hline employees & number & S5 & $\max$ & & & & \\
\hline \multicolumn{8}{|l|}{ Environmental indicators } \\
\hline fuel & $\mathrm{L}$ & ENV1 & $\min$ & seeding density & plants $/ \mathrm{m}^{2}$ & ENV5 & $\min$ \\
\hline water & $\mathrm{L} / \mathrm{kg}$ & ENV2 & $\min$ & seed quantity & g/year & ENV6 & $\min$ \\
\hline chemical fertilizers & $\mathrm{kg} / \mathrm{m}^{2}$ & ENV3 & $\min$ & agrochemicals & $\mathrm{L}$ & ENV7 & $\min$ \\
\hline organic fertilizers & $\mathrm{kg} / \mathrm{m}^{2}$ & ENV4 & $\min$ & irrigation surface & $\mathrm{m}^{2}$ & ENV8 & $\min$ \\
\hline
\end{tabular}

grown by farmer for self-consumption and represents a decrease in quantity devoted to sell. The other indicators (wild rocket crop sales; revenue; subsidies and government program payments; gross saleable production; a number of operating costs: e.g. fertilizers and crop protection costs, irrigation costs, fuel costs; certification costs; labour costs) contribute to represent the commercial profitability associated with wild rocket in each plantation. In detail, wild rocket crop sales represent the quantity sold by surface unit $\left(\mathrm{m}^{2}\right)$; revenue regards the quantity of wild rocket production unit per price (we considered the average of wild rocket market prices collected by Italian Institution for Agro-Food Market Services - ISMEA during the period considered for this study, i.e., 2012 and 2013); the amount of subsidies and institutional program payments refers to incentives and all institutional market-based instruments aimed at supporting the production of wild rocket in financial terms; gross saleable production includes revenues from sales of products and activities related to agriculture, as well as payments under the first pillar of the Common Agricultural Policy (CAP). Referring to the main costs, we included costs of operating and maintaining the wild rocket production activity, such as fertilizers and crop protection costs, irrigation costs, fuel costs, certification costs and labour costs.

Social or human impacts were assessed according to nine indicators (Table 3). Indicators were chosen on the basis of the important role played by the social function in multifunctional agriculture, in particular as regards the support to rural development and food safety (Golusin and Ivanović, 2009). In line with these aims, diversification refers to the presence of non-farm typical activities, which contribute to rural cohesion and vitality, while the percentage of land tenure regards the legal regime in which land is owned by a farmer. In addition, total farm area refers to the utilised agricultural area plus woodland, and other areas not used for agriculture, and the number of plots of land refers to the phenomenon of fragmentation, which affects the right scale of production to make marketing strategies cost effective. The primary products revenues indicator covers the incidence (\%) of the total value of commodity products in comparison to other agricultural outputs. These indicators seem to be able to describe the contribution a farm may offer to rural development and viability, since the retention of the agricultural population in the countryside is one of the main preconditions of sustainability. Moreover, employment and working places (employees, seasonal workers) could be described as liberalistic supplements that are connected with the local social development of rural areas. The farmers' educational qualification is an indicator of farmers' skills and may be important for diversification (European Union, 2015). It was measured as the obtained qualification level (i.e. primary education, secondary education, high school education, degree/PhD) and results in a four point scale. The presence of an organic production area puts emphasis on the effect of wild rocket growing on the environment. In addition, the use of minimum treatment of vegetables, the exclusion of synthetic products, for both disease protection and plant nutrition, means that a number of products that are cultivated could contribute in and increase food safety producing high-quality products.

Finally, eight environmental indicators were chosen to describe the environmental impacts of the different farming methods on renewable and non-renewable resources consumption (Table 3). As the information for environmental decisions is often poor or insufficient, we used these available indicators to define the environmental impact of the different farming systems we considered in this study. The use of limited environmental resources (water) and the irrigated surface were represented by specific indicators. The indicator "water" refers to the quantity of water used for cleaning wild rocket before sale and was expressed by using litres per kilogram. Similarly, the use of fuel, chemical and organic fertilizers and agrochemicals was reported to define the impacts on the environment (Radulescu et al., 2010). The density and the quantity of seed used contribute to describe the different environmental consequences of adopting one farming system instead of another. These environmental indicators were selected to describe the environmental quality of farming practices, including consumption patterns and specific farming processes.

As regards the direction of the indicator scores, we considered that for a number of indicators a higher score implies a "better" score, whereas for other indicators a higher score implies a "worse" score (Table 3). The direction of preferences was decided according to main orientation of stakeholders' preference (Keeney, 1988) with respect to sustainability in a context of wild rocket production and taking into account the meaning of multi-functionality of agriculture.

\subsection{Multi-criteria decision analysis}

Data were analysed by using VISA ${ }^{\circledast}$. The alternatives (cultivation methods) and criteria available were the basis for an evaluation matrix containing scores referring to the attributes for each alternative.

The first step in this method was assigning a measured value to each alternative for each of the attributes involved in the analysis. Considering $i=1,2,3$ farming methods evaluated by $j=1,2, \ldots, 29$ attributes, we obtained 87 outcomes that represented the value reached by the $i_{\text {th }}$ farming method when it was evaluated by the jth attribute.

As the attributes were measured in different units by using different 
Table 4

Normalized values.

\begin{tabular}{|c|c|c|c|c|c|c|c|c|c|c|}
\hline \multicolumn{11}{|c|}{ Farming methods"/Indicators } \\
\hline & E1 & $\mathrm{E} 2$ & E3 & E4 & E5 & E6 & E7 & E8 & E9 & E10 \\
\hline $\mathrm{C}$ & 1.155 & 1.141 & -0.577 & 1.089 & -0.227 & -0.577 & -0.230 & -0.486 & 1.153 & -0.775 \\
\hline B & -0.575 & -0.416 & -0.577 & -0.877 & -0.867 & -0.577 & -0.865 & -0.664 & -0.623 & 1.129 \\
\hline \multirow[t]{2}{*}{$\mathrm{O}$} & -0.580 & -0.725 & 1.155 & -0.212 & 1.094 & 1.155 & 1.095 & 1.150 & -0.530 & -0.354 \\
\hline & E11 & E12 & ENV1 & ENV2 & ENV3 & ENV4 & ENV5 & ENV6 & ENV7 & ENV8 \\
\hline $\mathrm{C}$ & -0.577 & -1.148 & 0.768 & -0.927 & 1.155 & -1.155 & 0.858 & 1.155 & 1.155 & 1.153 \\
\hline B & 1.155 & 0.469 & 0.363 & -0.132 & -0.577 & 0.577 & -1.098 & -0.583 & -0.577 & -0.623 \\
\hline \multirow[t]{2}{*}{$\mathrm{O}$} & -0.577 & 0.679 & -1.131 & 1.060 & -0.577 & 0.577 & 0.241 & -0.572 & -0.577 & -0.530 \\
\hline & S1 & S2 & S3 & S4 & S5 & S6 & S7 & S8 & S9 & \\
\hline C & 1.044 & -0.886 & -0.577 & -1.155 & -0.784 & 0.000 & -1.155 & 0.000 & -1.017 & \\
\hline B & -0.949 & -0.198 & -0.577 & 0.577 & 1.126 & -1.000 & 0.577 & -1.000 & 0.035 & \\
\hline $\mathrm{O}$ & -0.095 & 1.084 & 1.155 & 0.577 & -0.343 & 1.000 & 0.577 & 1.000 & 0.982 & \\
\hline
\end{tabular}

$* \mathrm{C}=$ conventional, $\mathrm{B}=$ biodynamic, $\mathrm{O}=$ organic.

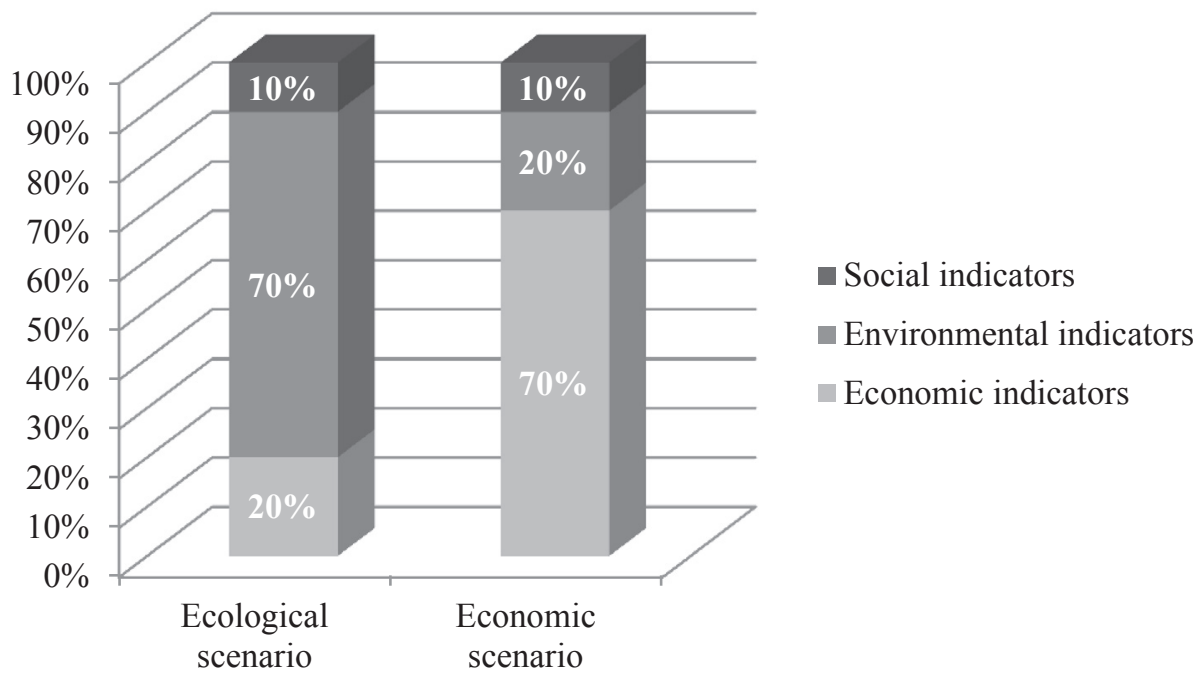

Fig. 1. Weighting scenarios and distribution among groups of indicators.

evaluation scales, it was necessary to normalize the values or scores $\left(\mathrm{s}_{\mathrm{ij}}\right)$ before aggregating them (Table 4). According to Pomerol and BarbaRomero (1993), no general rule can be used to select a specific evaluation scale. Mean scores and standard deviations were used in our study to normalize values: normalized score $r_{i j}=\left(s_{i j}-\right.$ mean $) /$ standard deviation, that is, each score minus the mean of the criterion concerned, and the result divided by the standard deviation of the criterion concerned.

Although the normalized matrix gives the opportunity of compiling an initial rank of alternatives, it was not possible to identify the best alternative by means of the principle of absolute Paretian dominance. The choice among alternatives was carried out by using the theory of value functions (Beinat, 1997; Kadziński et al., 2015; Keeney and Raiffa, 1976), which were assessed for each attribute, and a specific value was associated with each score to represent the preference in comparison to a limited context. Value functions are able to outline the scores profile of a farming method (an alternative) into a value. They were elicited by interviews with representatives of every stakeholder group. Since value functions for economic aspects (costs and time) depend on preference judgments (Beinat, 1997), we decided to take into consideration decision makers' opinions. Value functions for environmental aspects were the results of experts' assessment, as they concerned both factual and value judgement.

For the sake of simplicity, the stakeholders adopted a linear representation, which is based on the preference independence of the criteria (Keeney and Raiffa, 1976) being aware it is either an unrealistic assumption or a strong simplification. Nevertheless, it has been shown that this functions could generate results close to real contexts, even if substantially simplifying the models (Hwang and Yoon, 1981).

During focus groups we noticed that farmers and institutional makers supported different opinions about agricultural activities targets (i.e. more - although not exclusively - devoted to strong sustainability versus targeted to profit maximization). To take into consideration their different approaches, we decided to analyze different contexts. Two scenarios were examined. In the ecological scenario, that is intended to promote sustainability, the development does not support the quantitative increase of economic inputs of farming systems, but aims at maintaining the environmental resources. The economic scenario focuses on the economic performance of farming system and promotes the increase of profitability. As a result, according to the scenario chosen, some factors were emphasised, while others were not (i.e. the direction of optimization of a number of criteria changed).

According to stakeholders' opinions and for the sake of simplicity, the economic scenario assumes that the highest value of profitability must be chosen (e.g., "more revenue is better") minimizing the consideration of the maintenance of natural capital. The ecological scenario stresses the environmental performance of natural capital; consequently, for inputs with negative environmental impact (e.g., "less chemical fertilizers are better"), the lowest possible value must be selected. In the case of the ecological scenario, the most significant factors were those that enhance environmental quality and the reduction of agricultural practices, and in general anything that can damage the 


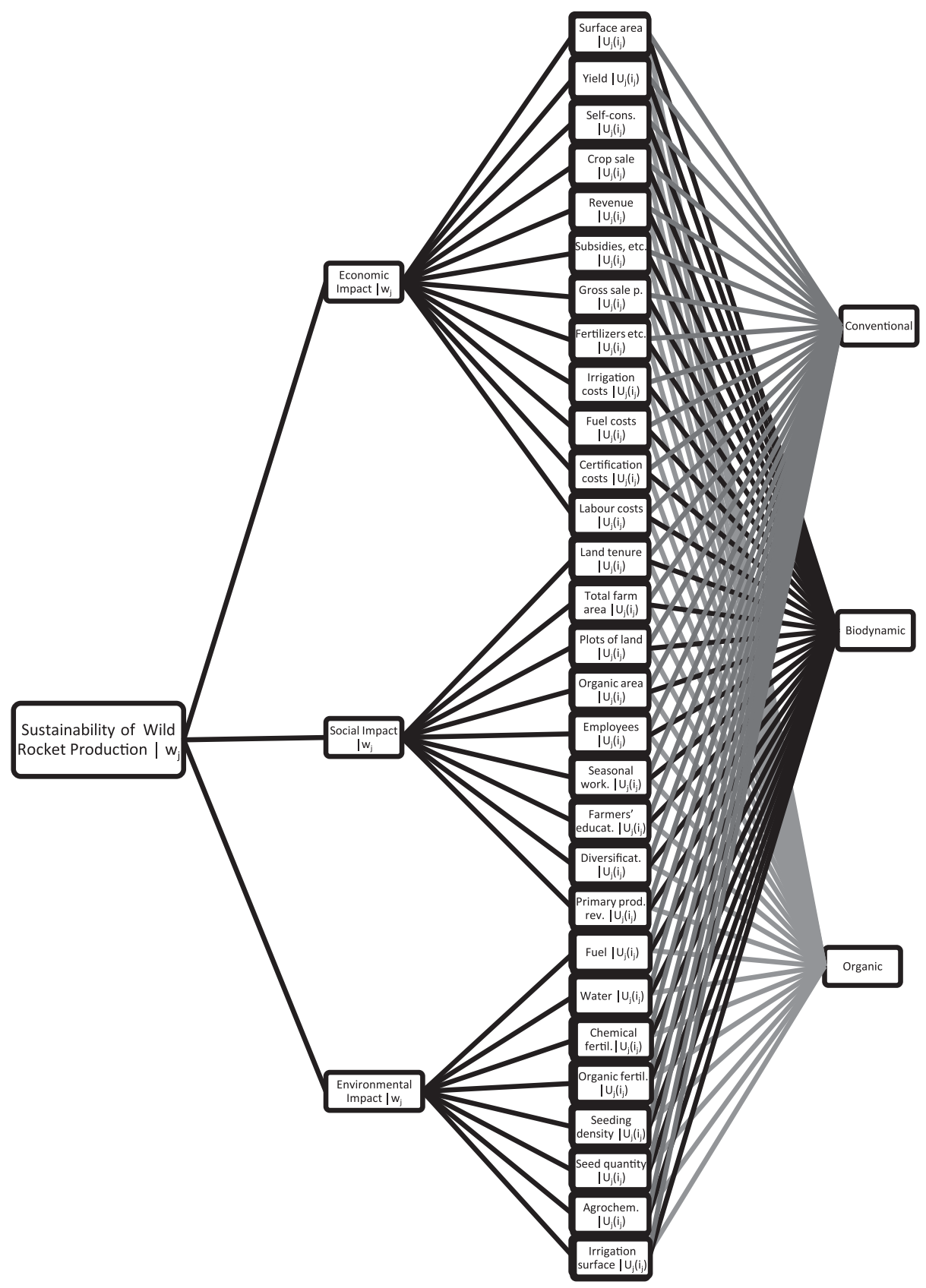

Fig. 2. Value tree of the MAVT model architecture for the case study relative to wild rocket cultivation.

environment. In the economic scenario, the emphasis was on pure economic utility deriving from agricultural practices that use different types of input almost unlimitedly, and without considering the repercussions on the environment.

The definitions of the value functions allowed to construct a utility matrix. Although in some cases the matrix already permits to rank the alternatives according to the performance-score profile, in our study it was necessary to find a method to gauge the importance of each attribute so that decisional alternatives could be ranked according to their weight, which expressed its relative importance. This task was quite difficult, since the final rank depends on the weighting allocated. Considering that Collier et al. (2014) identified the best weights as those compatible with the preferences revealed by the actors involved, we decided to create a focus group among stakeholders to assess and rate the importance of each attribute on the basis of their opinions. As a result of stakeholders engagement, a weighting system was adopted with the aim of evidencing the differences between a sustainable and a conventional management of agricultural practices (i.e., the scenario method) (De Brucker et al., 2004). In detail, according to preferences collected among multiple stakeholders, weights represented the relative importance of each indicator in each scenario (Collier et al., 2014; Tsang et al., 2014) (Fig. 1). The economic indicators had the highest importance or weighting factor and the environmental indicators had the lowest weighting factors in the economic scenario, while the opposite was true in the ecological scenario. The social indicators maintained the same weighting factors in both scenarios.

The attribution was carried out directly by multiplying the weighting to the indicators. We obtained a matrix of weighted utilities which gave a picture of the behaviour of each decisional alternative.

The method of identifying the relative importance of criteria is primarily established by the aggregation approach used (Rowley et al., 2012). We decided to use the weighted sum, which is the most common procedure in the MAVT (Beinat, 1997; Keeney and Raiffa 1976), to identify the function that described the utility deriving from the choice 
Table 5

Sowing and harvesting dates of wild rocket relative to the two years of investigation.

\begin{tabular}{|c|c|c|c|}
\hline & & 2012 & \\
\hline Farming methods* & $C$ & $O$ & $B$ \\
\hline Sowing date & March 21 & March 22 & March 21 \\
\hline Harvesting date & May 3 & May 4 & May 2 \\
\hline Sowing date & June 21 & June 18 & June 19 \\
\hline Harvesting date & July 12 & July 18 & July 16 \\
\hline Sowing date & September 7 & September 7 & September 7 \\
\hline \multirow[t]{2}{*}{ Harvesting date } & October 9 & October 15 & October 10 \\
\hline & & 2013 & \\
\hline Sowing date & March 26 & March 26 & March 26 \\
\hline Harvesting date & May 6 & May 10 & May 7 \\
\hline Sowing date & June 18 & June 18 & June 18 \\
\hline Harvesting date & July 11 & July 12 & July 16 \\
\hline Sowing date & September 13 & September 13 & September 13 \\
\hline Harvesting date & October 25 & October 25 & October 28 \\
\hline
\end{tabular}

* $\mathrm{C}=$ conventional, $\mathrm{B}=$ biodynamic, $\mathrm{O}=$ organic.

Table 6

Weighted decision matrix -Ecological scenario.

\begin{tabular}{llllllllllll}
\hline \multicolumn{2}{l}{ Farming methods $/$ Indicators } \\
\hline \multicolumn{1}{l}{ E1 } & E2 & E3 & E4 & E5 & E6 & E7 & E8 & E9 & E10 \\
\hline C & 0.017 & 0.017 & 0.017 & 0.017 & 0.005 & 0.000 & 0.005 & 0.015 & 0.000 & 0.017 \\
B & 0.000 & 0.003 & 0.017 & 0.000 & 0.000 & 0.000 & 0.000 & 0.017 & 0.017 & 0.000 \\
O & 0.000 & 0.000 & 0.000 & 0.006 & 0.017 & 0.017 & 0.017 & 0.000 & 0.016 & 0.013 \\
& & E11 & E12 & ENV1 & ENV2 & ENV3 & ENV4 & ENV5 & ENV6 & ENV7 & ENV8 \\
C & 0.017 & 0.017 & 0.000 & 0.088 & 0.000 & 0.088 & 0.000 & 0.000 & 0.000 & 0.000 \\
B & 0.000 & 0.002 & 0.019 & 0.053 & 0.088 & 0.000 & 0.088 & 0.088 & 0.088 & 0.088 \\
O & 0.017 & 0.000 & 0.088 & 0.000 & 0.088 & 0.000 & 0.028 & 0.087 & 0.088 & 0.083 \\
& S1 & S2 & S3 & S4 & S5 & S6 & S7 & S8 & S9 & \\
C & 0.011 & 0.000 & 0.011 & 0.000 & 0.000 & 0.006 & 0.000 & 0.006 & 0.011 & \\
B & 0.000 & 0.004 & 0.011 & 0.011 & 0.011 & 0.011 & 0.011 & 0.000 & 0.005 & \\
O & 0.005 & 0.011 & 0.000 & 0.011 & 0.003 & 0.000 & 0.011 & 0.011 & 0.000 & \\
\hline
\end{tabular}

$* \mathrm{C}=$ conventional, $\mathrm{B}=$ biodynamic, $\mathrm{O}=$ organic.

Table 7

Weighted decision matrix - Economic scenario.

\begin{tabular}{lllllllllll}
\hline \multicolumn{2}{l}{ Farming methods"/Indicators } \\
\hline \multicolumn{1}{l}{ E1 } & E2 & E3 & E4 & E5 & E6 & E7 & E8 & E9 & E10 \\
\hline C & 0.058 & 0.058 & 0.058 & 0.058 & 0.019 & 0.000 & 0.019 & 0.053 & 0.000 & 0.058 \\
B & 0.000 & 0.010 & 0.058 & 0.000 & 0.000 & 0.000 & 0.000 & 0.058 & 0.058 & 0.000 \\
O & 0.000 & 0.000 & 0.000 & 0.020 & 0.058 & 0.058 & 0.058 & 0.000 & 0.055 & 0.045 \\
& E11 & E12 & ENV1 & ENV2 & ENV3 & ENV4 & ENV5 & ENV6 & ENV7 & ENV8 \\
C & 0.058 & 0.058 & 0.000 & 0.025 & 0.000 & 0.025 & 0.000 & 0.000 & 0.000 & 0.000 \\
B & 0.000 & 0.007 & 0.005 & 0.015 & 0.025 & 0.000 & 0.025 & 0.025 & 0.025 & 0.025 \\
O & 0.058 & 0.000 & 0.025 & 0.000 & 0.025 & 0.000 & 0.008 & 0.025 & 0.025 & 0.024 \\
& S1 & S2 & S3 & S4 & S5 & S6 & S7 & S8 & S9 & \\
C & 0.011 & 0.000 & 0.011 & 0.000 & 0.000 & 0.006 & 0.000 & 0.006 & 0.011 & \\
B & 0.000 & 0.004 & 0.011 & 0.011 & 0.011 & 0.011 & 0.011 & 0.000 & 0.005 & \\
O & 0.005 & 0.011 & 0.000 & 0.011 & 0.003 & 0.000 & 0.011 & 0.011 & 0.000 &
\end{tabular}

$* \mathrm{C}=$ conventional, $\mathrm{B}=$ biodynamic, $\mathrm{O}=$ organic.

of an alternative. The weighted sum is a basic but typical method to calculate the overall value score for an alternative as a linear weighted sum of its records across a number of criteria, i.e., $\mathrm{V}=\Sigma_{\mathrm{j}} \mathrm{w}_{\mathrm{j}} \mathrm{X}_{\mathrm{j}}$, where $\Sigma_{\mathrm{j}} \mathrm{w}_{\mathrm{j}}=1$ (Huang et al., 2011). The weighted sum uses various assumptions and has its own advantages and disadvantages, which will affect its suitability to any given decision problem contexts (Rehman and Romero, 1993). Since MAVT is based on the concept of a trade-off among different criteria's scores, a complete compensation between attributes is always possible. Nevertheless, according to Keeney and
Raiffa (1976), if an appropriate utility is attributed to each possible consequence and the expected utility of each alternative is computed, what is achieved as the best choice is the alternative with the highest expected utility. Moreover, because of their transparency and manageability in implementation, this method has been often applied in real situations. Using MAVT, each alternative is ranked on the basis of its overall utility $U\left(i_{j}\right)$, which takes into consideration the performance of an alternative (i) on each considered criterion (j), i.e. $U_{j}\left(i_{j}\right)$.

Consequently, the alternatives were ranked by using cardinal values. A single value included all the weighted utilities linked to each alternative. The model we used for this case study can be described by a value tree (Fig. 2).

A sensitivity analysis was performed to understand the stability of the results obtained.

As the aim of this investigation was to determine the validity range of the results and to set up an operating recommendation, afterwards a workshop was held, where the results were presented and stakeholders were asked to evaluate their prior valuation of preferences.

\section{Results}

We tried to limit the influence of a number of variability parameters that can play a role on the characteristics of the product, to obtain a comparison that may be as much valid as possible among the three different farming methods. In particular, in the case of rocket it is well known that the characteristics of the product may be influenced by parameters as climatic conditions (atmospheric humidity, air temperature, luminosity), genetic factors of the plant, maturation stage, growing period of the year (Guadagnin et al., 2005; Muramoto, 1999; Santamaria et al., 2001). Therefore, we decided to carry on the research on a rather limited geographical area in order to minimize the variability of the environmental parameters, and in particular of the climatic conditions. However, the specific techniques adopted in the three farms that took part in the investigation were not optimized: the producers continued to work in line with the production habits usually adopted, as the aim of the research was to obtain results showing the productive situation of the territory. Some operational parameters were agreed (a single stock of seeds was used by all the three farms during both years of production to minimize the influence of the genetic factors; the seeding days were agreed for spring, summer and autumn seedings of both years to minimize the influence of the growing period of the year). On the contrary, rocket was harvested in different days, when the product was ready for commercialization. The days of both seeding and harvesting relative to the experimental design of both years are shown in Table 5.

Luminosity was very similar inside the greenhouses of the three farms, as the roofing material was the same and also the age of the sheets was very similar in all cases; as a consequence, luminosity variations were limited to $\pm 15 \%$. Therefore, it can be stated that luminosity variations had little (if any) influence on the parameters that have been taken into account to carry out this investigation.

The results of the MAVT documented the ranking and relative significance of each indicator in relation to the achievement of the mission of each scenario. The corresponding weighted decision matrices (Tables 6 and 7) permitted evaluations of alternatives by scores after weighting coefficients to express the importance of each criterion. The weighted decision matrices were calculated by multiplying the elements of the normalized utility matrix by the appropriate criteria weights (Table 8). All the values are positive, since scores of utility matrix scaled from 1 to 0 by using value functions.

In the weighted decision matrix, the higher values of evaluation scores mean a better performance and the final target is to maximize the result of decision. The performance of alternative $\mathrm{C}, \mathrm{B}, \mathrm{O}$ against criterion "ecological/economic scenario" was denoted by evaluation scores.

The aggregation of the results gave the opportunity to calculate the 
Table 8

Normalized weight of each indicator.

\begin{tabular}{|c|c|c|c|c|c|c|c|c|c|c|}
\hline \multicolumn{11}{|c|}{ Scenario"/Indicators } \\
\hline & E1 & E2 & E3 & E4 & E5 & E6 & E7 & E8 & E9 & E10 \\
\hline Ecological & 0.0167 & 0.0167 & 0.0167 & 0.0167 & 0.0167 & 0.0167 & 0.0167 & 0.0167 & 0.0167 & 0.0167 \\
\hline \multirow[t]{2}{*}{ Economic } & 0.0583 & 0.0583 & 0.0583 & 0.0583 & 0.0583 & 0.0583 & 0.0583 & 0.0583 & 0.0583 & 0.0583 \\
\hline & E11 & E12 & ENV1 & ENV2 & ENV3 & ENV4 & ENV5 & ENV6 & ENV7 & ENV8 \\
\hline Ecological & 0.0167 & 0.0167 & 0.0875 & 0.0875 & 0.0875 & 0.0875 & 0.0875 & 0.0875 & 0.0875 & 0.0875 \\
\hline \multirow[t]{2}{*}{ Economic } & 0.0583 & 0.0583 & 0.025 & 0.025 & 0.025 & 0.025 & 0.025 & 0.025 & 0.025 & 0.025 \\
\hline & S1 & S2 & S3 & S4 & S5 & S6 & S7 & S8 & S9 & \\
\hline Ecological & 0.0111 & 0.0111 & 0.0111 & 0.0111 & 0.0111 & 0.0111 & 0.0111 & 0.0111 & 0.0111 & \\
\hline Economic & 0.0111 & 0.0111 & 0.0111 & 0.0111 & 0.0111 & 0.0111 & 0.0111 & 0.0111 & 0.0111 & \\
\hline
\end{tabular}

Table 9

Ranking of alternatives.

\begin{tabular}{lllll}
\hline \multicolumn{5}{l}{ Farming methods"/Scenarios } \\
\cline { 2 - 5 } & Ecological scenario & & Economic scenario \\
\hline C & 0.362 & 3rd & 0.593 & 1st \\
B & 0.628 & 1st & 0.402 & 3rd \\
O & 0.613 & 2nd & 0.537 & 2nd \\
\hline
\end{tabular}

$* \mathrm{C}=$ conventional, $\mathrm{B}=$ biodynamic, $\mathrm{O}=$ organic.

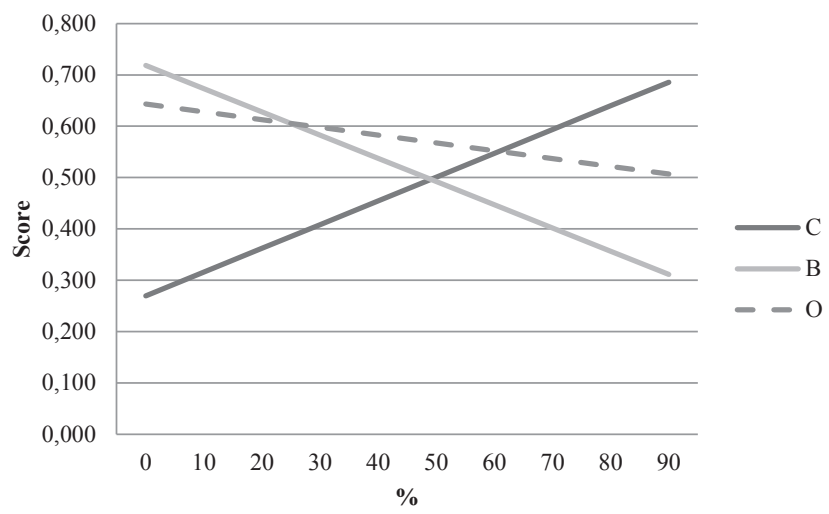

$\mathrm{C}=$ conventional, $\mathrm{B}=$ biodynamic, $\mathrm{O}=$ organic

Fig. 3. Sensitivity of the alternative ranking with respect to changes in the weight assigned to economic indicators.

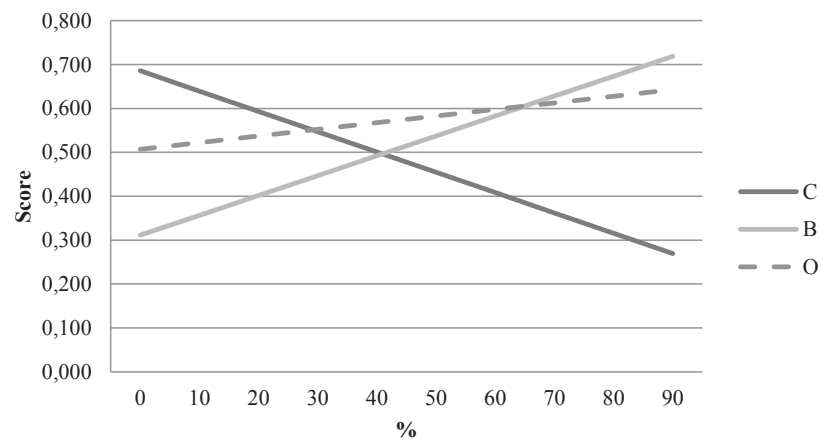

$\mathrm{C}=$ conventional, $\mathrm{B}=$ biodynamic, $\mathrm{O}=$ organic

Fig. 4. Sensitivity of the alternative ranking with respect to changes in the weight assigned to environmental indicators.

total value of each specific alternative (Table 9).

Our findings showed that the weighted sum was different in the two scenarios. In the ecological scenario, the range of values was wider than in the economic scenario. There was an overlapping of the lists, because the positions assumed by the organic farm in the two hypotheses was the same. Considering a pure rational economic behaviour (economic scenario), the conventional farm had the best result. In this case, wild rocket production was not hindered by its environmental and human health impacts. In fact, decision-making in the conventional farm is mainly led by profit maximization, although avoiding environmental risks for human health is also taken into account, while the biodynamic farm takes into consideration mainly environmental and social aspects. In the ecological scenario the first position was occupied by the biodynamic farm, which is very sensitive to human impacts on environmental resources. Therefore, according to sustainable principles, this farm manages environmental resources with the awareness that they need to be safeguarded, and it tries to reconcile the simultaneous presence of natural capital with socio-economic development. Nevertheless, regarding the organic farm, the results from the present study confirm that this type of agriculture plays an important role in obtaining positive economic results, by safeguarding the environment and creating benefits for the whole community. In detail, our findings put in evidence the ability of this farming system to balance and reach equilibrium among all the dimensions of sustainability (Table 9).

According to Convertino et al. (2013), subjectivity strongly affects the evaluation of alternatives. Consequently, the analysis of the sensitivity to changes in the factor scores was performed in order to understand how the results obtained through weighting can vary (Linkov and Moberg, 2011). This analysis was carried out by considering the ranking for all possible values of the weight of both group of economic and environmental indicators at a time. Having the social indicators the same weights for both scenarios, we omitted their sensitivity analysis. The results are summarized in the graphs of Figs. 3 and 4.

As it can be seen, for both group weights, there are reversal points between conventional, biodynamic and organic farming methods (the three lines that represent these methods crossed one another). This means that farming methods rank differently, since it matters how much the weight value is changed. Rank reversals did occur with all farming methods. However, while reversal points for conventional and biodynamic methods are located far from the original weight values, rank reversals for biodynamic and organic systems are located closer. Consequently, shifts in how criteria are weighted could have impacts on relative ranking, but we can appreciate significant ranking order variations only with consistent changes.

\section{Discussion and conclusions}

Choosing the most suitable farming method for reaching an equilibrium among the principles of sustainability is a complex task as it must take into account a number of criteria; each of them has different effects on the final decision. Nevertheless, this problem can be treated as a multi-criteria decision problem. According to Callo-Concha and Denich (2014), although this approach is not innovative, its intrinsic flexibility, which can deal with multiple features adapted to different farmers' needs, seems able to reduce the limitations of other conventional 
methods, and works as a support for decision-making. If more than one decision-maker participates in the decision process, this becomes more complicated and under certain conditions it could be easily considered a group decision-making problem (Dragincic et al., 2015). Laforest et al. (2013) stated that MCDM enables to rank and choose the farming methods that are the most adapted to a particular farm, by taking into account not only purely economic or financial criteria, but also social and environmental criteria, and informs farmers by comparing a number of farming methods simultaneously.

The system for evaluation of sustainable agriculture takes into consideration different objectives and enables precise ranking of each analysed scenario.

This paper proposes multi-criteria analysis for selecting the most suitable farming method for wild rocket cultivation in order to reach consensus between decision-makers. In particular, we chose MAVT as it is comprehensible to be implemented, and helps decision-makers, and, more specifically, farmers, to take their preferences into consideration and make decisions in conformity with their goals (Munda, 2006). In particular, MAVT allowed an exhaustive evaluation of the different wild rocket farming systems we analysed in our study, as it took into consideration economic, social and environmental aspects during decisionmaking process.

The results of these field tests, the knowledge of local stakeholders and the systematic approach to the problem of MCDM were combined to assess and select the most suitable farming method in order to support the multifunctional role of cultivation systems. The obtained results confirmed that organic farming plays an important role in obtaining positive economic results, by safeguarding the environment and creating benefits for the whole community. Moreover, it is able to balance and reach equilibrium among all the dimensions of sustainability.

Conversion from conventional to biodynamic farming seems to be a valuable contribution to improve environmental performances providing a great mitigation potential within agricultural practices. The need to innovate farming systems is in response to various external pressures, including a declining stock of environmental resources and climate change. Biodynamic farming seems to be able to embrace the ethics, practices, and economic benefits of organic production and to improve its environmental benefits, since it succeeds in working towards closed loops (March et al., 2016). The biodynamic agricultural method can be considered a holistic approach to sustainability (Kovacevic and Lazic, 2012; Ponzio et al., 2013).

However, the main limitations of the present study are due to the fact that the results obtained simply represent a first tentative of application of the MAVT methodology to the productive reality of the territory of the province of Udine, as only three farms have been involved. It would be important to extend the research to other farms of the same or of different territories to better understand their behaviour. Despite the limitations of our study, we believe our results can add useful data to currently available literature on assessing the multifunctional role of different farming systems. In addition, although the empirical data used to test the framework were based on regional information, this theoretical approach could be applied in several local decision-making situations to assess the sustainability impacts of wild rocket production at a broader level. In fact, the issues of this study may be of interest to researchers and decision-makers of different regions, as many of the characteristics of the examined region are similar to the characteristics of other Italian and European regions. Furthermore, our findings should be useful for farmers in areas where the development of sustainable wild rocket production can be an important element for the improvement of the multifunctional role of agricultural activities and their production of public goods (Troiano and Marangon, 2010). These results can give indications also to public administrators in order to both favour the choice of cultivation techniques that are more sustainable for the territory and support the farmers in their decisions. Previous experiences showed that results of interest can be obtained by the dialogue between all the stakeholders involved. Moreover, findings could be useful to farmers to determine the production system and to identify the most accurate and sustainable farming practices.

Taking into account their decision variables, aims and constraints, farmers could maximize their personal utility function, as the use of MCDM is not time consuming and allows to consider and manage at the same time all the criteria and solve the decision-making problem. Moreover, this approach can be used by farmers for selecting the most suitable farming system for wild rocket in other regions, although, according to Dragincic et al. (2015), due to the specific characteristics of each study area to implement MCDM, it is necessary to consider local stakeholders' knowledge and experience, which would possibly add, remove or change important criteria/indicators that we used in our study. Finally, data and information given by the producers of the three farms that took part in the research might be used also for other purposes, like for carrying on a LCA analysis in order to increase the set of environmental indicators (Wang et al., 2016).

This research did not receive any specific grant from funding agencies in the public, commercial, or not-for-profit sectors.

\section{References}

Andreoli, M., Tellarini, V., 2000. Farm sustainability evaluation: methodology and practice. Agric. Ecosyst. Environ. 77 (1), 43-52.

Beinat, E., 1997. Value Functions for Environmental Management. Kluwer Academic Publishers, Dordrecht.

Binder, C.R., Feola, G., Steinberger, J.K., 2010. Considering the normative, systemic and procedural dimensions in indicator-based sustainability assessments in agriculture. Environ. Impact. Assess. Rev. 30 (2), 71-81.

Bockstaller, C., Guichard, L., Keichinger, O., Girardin, P., Galan, M.B., Gaillard, G., 2009. Comparison of methods to assess the sustainability of agricultural systems: a review. Agron. Sustain. Dev. 29 (1), 223-235.

Callo-Concha, D., Denich, M., 2014. A participatory framework to assess multifunctional land-use systems with multicriteria and multivariate analyses: a case study on agrobiodiversity of agroforestry systems in Tomé Açú, Brazil. Change Adapt. Socioecol. Syst. 1, 40-50.

Cardín-Pedrosa, M., Alvarez-López, C.J., 2012. Reprint of: model for decision-making in agricultural production planning. Comput. Electron. Agric. 86, 131-139.

Carof, M., Colomb, B., Aveline, A., 2013. A guide for choosing the most appropriate method for multi-criteria assessment of agricultural systems according to decisionmakers' expectations. Agric. Syst. 115, 51-62.

Castellini, C., Boggia, A., Cortina, C., Dal Bosco, A., Paolotti, L., Novelli, E., Mugnai, C., 2012. A multicriteria approach for measuring the sustainability of different poultry production systems. J. Clean. Prod. 37, 192-201.

Cattivello, C., 2013. L'orticoltura regionale ai tempi della crisi. Risultati ed analisi di un censimento. Notiziario ERSA. 1, pp. 16-24.

Cegan, J.C., Filion, A.M., Keisler, J.M., Linkov, I., 2017. Trends and applications of multicriteria decision analysis in environmental sciences: literature review. Environ. Syst. Decis. 37, 123-133.

Cerny, M.S., Taube, E., Battaglia, R., 1996. Identification of bis(4-isothiocyanatobutyl) disulphide and its precursor from rocket salad (Eruca sativa). J. Agric. Food. Chem. 44, 3835-3839.

Collier, Z.A., Bates, M.E., Wood, M.D., Linkov, I., 2014. Stakeholder engagement in dredged material management decisions. Sci. Total Environ. 496, 248-256.

Convertino, M., Baker, K.M., Vogel, J.T., Lu, C., Suedel, B., Linkov, I., 2013. Multi-criteria decision analysis to select metrics for design and monitoring of sustainable ecosystem restorations. Ecol. Indic. 26, 76-86.

Dantsis, T., Douma, C., Giourga, C., Loumou, A., Polychronaki, E.A., 2010. A methodological approach to assess and compare the sustainability level of agricultural plant production systems. Ecol. Indic. 10, 256-263.

De Brucker, K., Verbeke, A., Macharis, C., 2004. The applicability of multicriteria-analysis to the evaluation of intelligent transport systems (ITS). Res. Transport. Econ. 8, 151-179.

Diaz-Balteiro, L., González-Pachón, J., Romero, C., 2017. Measuring systems sustainability with multi-criteria methods: a critical review. Eur. J. Oper. Res. 258, 607-616.

Dragincic, J., Korac, N., Blagojevic, B., 2015. Group multi-criteria decision making (GMCDM) approach for selecting the most suitable table grape variety intended for organic viticulture. Comput. Electron. Agric. 111, 194-202.

Dyer, J.S., 2016. Multiattribute Utility Theory (MAUT). In: Greco, S., Ehrgott, M., Figueira, J.R. (Eds.), Multiple Criteria Decision Analysis. Springer, New York, USA, pp. 285-314.

European Union, 2015. Comparison of farmers' incomes in the EU member states, European Parliament's Committee on Agriculture and Rural Development. http:// www.europarl.europa.eu/RegData/etudes/STUD/2015/540374/IPOL_STU(2015) 540374_EN.pdf (accessed on 1st February 2017).

Fagioli, F.F., Rocchi, L., Paolotti, L., Słowiński, R., Boggia, A., 2017. From the farm to the agri-food system: a multiple criteria framework to evaluate extended multi-functional value. Ecol. Indic. 79, 91-102.

Gerbens-Leenes, P.W., Moll, H.C., Uiterkamp, A.S., 2003. Design and development of a 
measuring method for environmental sustainability in food production systems. Ecol. Econ. 46 (2), 231-248.

Golusin, M., Ivanović, O.M., 2009. Definition, characteristics and state of the indicators of sustainable development in countries of Southeastern Europe. Agric. Ecosyst. Environ. 130 (1), 67-74.

Gómez-Limón, J.A., Riesgo, L., Arriaza, M., 2004. Multi-criteria analysis of input use in agriculture. J. Agric. Econ. 55 (3), 541-564.

Guadagnin, S.G., Rath, S., Reyes, F.G.R., 2005. Evaluation of the nitrate content in leaf vegetables produced through different agricultural systems. Food Addit. Contam. 22 (12), 1203-1208.

Hayashi, K., 2000. Multicriteria analysis for agriculture resource management: a critical survey and future perspectives. Eur. J. Oper. Res. 122, 486-500.

Hermann, B.G., Kroeze, C., Jawjit, W., 2007. Assessing environmental performance by combining life cycle assessment, multi-criteria analysis and environmental performance indicators. J. Clean. Prod. 15, 1787-1796.

Huang, I.B., Keisler, J., Linkov, I., 2011. Multi-criteria decision analysis in environmental sciences: ten years of applications and trends. Sci. Total Environ. 409 (19), 3578-3594.

Hwang, C.L., Yoon, K., 1981. Multiple attribute decision making. Methods and Applications. A State of the Art Survey. Springer-Verlag, New York.

Janeiro, L., Patel, M.K., 2015. Choosing sustainable technologies. Implications of the underlying sustainability paradigm in the decision-making process. J. Clean. Prod. 105, 438-446.

Jeswani, H.K., Azapagic, A., Schepelmann, P., Ritthoff, M., 2010. Options for broadening and deepening the LCA approaches. J. Clean. Prod. 18, 120-127.

Kadziński, M., Ciomek, K., Słowiński, R., 2015. Modelling assignment-based pairwise comparisons within integrated framework for value-driven multiple criteria sorting. Eur. J. Oper. Res. 241, 830-841.

Keeney, R.L., 1992. Value-Focused Thinking: a Path to Creative Decision making. Harvard University Press, Cambridge.

Keeney, R.L., 1988. Structuring objectives for problems of public interest. Oper. Res. 36 (3), 396-405.

Keeney, R.L., Raiffa, H., 1993. Decisions with Multiple Objectives: Preferences and Value Trade-offs. Cambridge University Press.

Keeney, R.L., Raiffa, H., 1976. Decisions with multiple objectives. Preferences and Value Tradeoffs. John Wiley \& Sons, New York.

Koukounaras, A., Siomos, A.S., Sfakiotakis, E., 2007. Postharvest $\mathrm{CO}_{2}$ and ethylene production and quality of rocket (Eruca sativa Mill.) leaves as affected by leaf age and storage temperature. Postharvest Biol. Technol. 46, 167-173.

Kovacevic, D., Lazic, B., 2012. Modern trends in the development of agriculture and demands on plant breeding and soil management. Genetica 44 (1), 201-216.

Kurth, M.H., Larkin, S., Keisler, J.M., Linkov, I., 2017. Trends and applications of multicriteria decision analysis: use in government agencies. Environ. Syst. Decis. 37, 134-143.

Kylili, A., Christoforou, E., Fokaides, P.A., Polycarpou, P., 2016. Multicriteria analysis for the selection of the most appropriate energy crops: the case of Cyprus. Int. J. Sustain. Energy 35, 47-58.

Laforest, V., Raymond, G., Piatyszek, É., 2013. Choosing cleaner and safer production practices through a multi-criteria approach. J. Clean. Prod. 47, 490-503.

Linkov, I., Moberg, E., 2011. Multi-Criteria Decision Analysis: Environmental Applications and Case Studies. CRC Press, Boca Raton.

Luyet, V., Schlaepfer, R., Parlange, M.B., Buttler, A., 2012. A framework to implement stakeholder participation in environmental projects. J. Environ. Manage. 111, 213-219.

Marangon, F., Tempesta, T., 1998. Rural landscape and economic results of the farm: a survey through a multi-objective approach. In: Beinat, E., Nijkamp, P. (Eds.), Multicriteria Evaluation in Land-Use Management: Methodologies and Case Studies. Kluwer Academic Publishers, Dordrecht, pp. 49-60.

March, M.D., Toma, L., Stott, A.W., Roberts, D.J., 2016. Modelling phosphorus efficiency within diverse dairy farming systems - pollutant and non-renewable resource? Ecol. Indic. 69, 667-676.

Meyer-Aurich, A., 2005. Economic and environmental analysis of sustainable farming practices-a Bavarian case study. Agric. Syst. 86, 190-206.

Montazar, A., Snyder, R.L., 2012. A multi-attribute preference model for optimal irrigated crop planning under water scarcity conditions. Span. J. Agric. Res. 10 (3), 826-837.

Munda, G., 2012. Multicriteria Evaluation in a Fuzzy Environment: Theory and Applications in Ecological Economics. Springer Science \& Business Media.

Munda, G., 2006. Social multi-criteria evaluation for urban sustainability policies. Land Use Pol. 23 (1), 86-94.

Munda, G., 2005. Multiple criteria decision analysis and sustainable development. In: Figueira, J., Greco, S., Ehrgott, M. (Eds.), Multiple Criteria Decision Analysis: State of the Art Surveys. Springer, Boston, USA, pp. 953-986.

Muramoto, J., 1999. Comparison of Nitrate Content in Leafy Vegetables from Organic and Conventional Farms in California, Centre for Agro Ecology and Sustainable Food System. University of California Santa Cruz, 1-66. http://128.121.182.245/documents/Joji/leafnitrate.pdf. (accessed on 3rd February 2017).

Nicoletti, R., Raimo, F., Miccio, G., 2007. Diplotaxis tenuifolia: biology, production and properties. Eur. J. Plant Sci. Biotechnol. 1 (1), 36-43.

Ortuño, M.T., Vitoriano, B., 2011. A goal programming approach for farm planning with resources dimensionality. Ann. Oper. Res. 190 (1), 181-199.

Parra-López, C., Calatrava-Requena, J., de-Haro-Giménez, T., 2008. A systemic comparative assessment of the multifunctional performance of alternative olive systems in Spain within an AHP-extended framework. Ecol. Econ. 64 (4), 820-834.

Parra-López, C., Calatrava-Requena, J., de-Haro-Giménez, T., 2007. A multi-criteria evaluation of the environmental performances of conventional, organic and integrated olive-growing systems in the south of Spain based on experts' knowledge. Renew. Agric. Food Syst. 22 (3), 189-203.

Piech, B., Rehman, T., 1993. Application of multiple criteria decision making methods to farm planning: a case study. Agric. Syst. 41 (3), 305-319.

Pomerol, J.C., Barba-Romero, S., 1993. Choix multicritère dans l'entreprise: principes et pratique. Hermès, Paris, France.

Ponzio, C., Gangatharan, R., Neri, D., 2013. Organic and biodynamic agriculture: a review in relation to sustainability. Int. J. Plant Soil Sci. 2 (1), 95-110.

Power, A.G., 2010. Ecosystem services and agriculture: tradeoffs and synergies. Philos. Trans. R. Soc. Lond., B Biol. Sci. 365, 2959-2971.

Pretty, J., 2003. Social capital and the collective management of resources. Science 302, 1912-1915.

Radulescu, C.Z., Turek Rahoveanu, A., Radulescu, M., 2010. A hybrid multi-criteria method for performance evaluation of Romanian South Muntenia Region in context of sustainable agriculture. September 15-17 In: Deo, N., Demiralp, M., Stork, M., Milkova, E., Wakamatsu, H., Tchizawa, K. (Eds.), Proc. Int. Conf. Appl. Comput. Sci., Malta. Wseas Press, pp. 291-296.

Ramírez-García, J., Carrillo, J.M., Ruiz, M., Alonso-Ayuso, M., Quemada, M., 2015. Multicriteria decision analysis applied to cover crop species and cultivars selection. Field Crop. Res. 175, 106-115.

Rehman, T., Romero, C., 1993. The application of the MCDM paradigm to the management of agriculture systems: some basic considerations. Agric. Syst. 41 (3), 239-255.

Riesgo, L., Gomez-Limon, J.A., 2006. Multi-criteria policy scenario analysis for public regulation of irrigated agriculture. Agric. Syst. 91 (1), 1-28.

Roy, B., Słowiński, R., 2013. Questions guiding the choice of a multicriteria decision aiding method. EURO J. Decis. Process. 1 (1-2), 69-97.

Rozman, Č., Pazek, K., Bavec, F., Bavec, M., Turk, J., Majkovič, D., 2006. A multi-criteria analysis of spelt food processing alternatives on small organic farms. J. Sustain. Agric. 28 (2), 159-179.

Rowley, H.V., Peters, G.M., Lundie, S., Moore, S.J., 2012. Aggregating sustainability indicators: beyond the weighted sum. J. Environ. Manage. 111, 24-33.

Saaty, T.L., Ergu, D., 2015. When is a decision-making method trustworthy? Criteria for evaluating multi-criteria decision-making methods. Int. J. Inf. Technol. Decis. Mak. $14,1-17$.

Sadok, W., Angevin, F., Bergez, J.-E., Bockstaller, C.B., Colomb, B., Guichard, L., Reau, R., Messéan, A., Doré, T., 2009. MASC, a qualitative multi-attribute decision model for ex ante assessment of the sustainability of cropping systems. Agron. Sustain. Dev. 29 (3), 447-461.

Sadok, W., Angevin, F., Bergez, J.-E., Bockstaller, C.B., Colomb, B., Guichard, L., Reau, R., Doré, T., 2008. Ex ante assessment of the sustainability of alternative cropping systems: implications for using multi-criteria decision-aid methods. A review. Agron. Sustain. Dev. 28, 163-174.

Santamaria, P., Gonella, M., Parente, A., Serio, F., 2001. Ways of reducing rocket salad nitrate content, Proceedings of International Symposium on Growing Media and Hydroponics, ISHS. Acta Hortic. 548, 529-536.

Tilman, D., Balzer, C., Hill, J., Befort, B., 2011. Global food demand and the sustainable intensification of agriculture. Proc. Natl. Acad. Sci. U.S.A. 50, 20260-20264.

Troiano, S., Marangon, F., 2010. Payments for Ecosystem Services: development opportunities from landscape and environmental resources management. Econ. Policy Energy Environ. 3, 87-113.

Tsang, M.P., Bates, M.E., Madison, M., Linkov, I., 2014. Benefits and risks of emerging technologies: integrating life cycle assessment and decision analysis to assess lumber treatment alternatives. Environ. Sci. Technol. 48, 11543-11550.

Van Calker, K.J., Berentsen, P.B.M., Romero, C., Giesen, G.W.J., Huirne, R.B.M., 2006. Development and application of a multi-attribute sustainability function for Dutch dairy farming systems. Ecol. Econ. 57 (4), 640-658.

Vučijak, B., Kurtagić, S.M., Silajdžić, I., 2015. Multicriteria decision making in selecting best solid waste management scenario: a municipal case study from Bosnia and Herzegovina. J. Clean. Prod. 130, 166-174.

Yatsalo, B.I., Kiker, G.A., Kim, J., Bridges, T.S., Seager, T.P., Gardner, K., Satterstrom, F.K., Linkov, I., 2007. Application of multicriteria decision analysis tools to two contaminated sediment case studies. Integr. Environ. Assess. Manage. 3 (2), 223-233.

Wang, X., Wu, X., Yan, P., Gao, W., Chen, Y., Sui, P., 2016. Integrated analysis on economic and environmental consequences of livestock husbandry on different scale in China. J. Clean. Prod. 119, 1-12.

Werner, A., Werner, A., Wieland, R., Kersebaum, K.C., Mirschel, W., Ende, H.P., Wiggering, H., 2014. Ex ante assessment of crop rotations focusing on energy crops using a multi-attribute decision-making method. Ecol. Indic. 45, 110-122.

Würtenberger, L., Koellner, T., Binder, C.R., 2006. Virtual land use and agricultural trade: estimating environmental and socio-economic impacts. Ecol. Econ. 57 (4), 679-697.

Zahm, F., Viaux, P., Vilain, L., Girardin, P., Mouchet, C., 2008. Assessing farm sustainability with the IDEA method-from the concept of agriculture sustainability to case studies on farms. Sustain. Dev. 16 (4), 271-281.

Zhang, H., Haapala, K.R., 2015. Integrating sustainable manufacturing assessment into decision making for a production work cell. J. Clean. Prod. 105, 52-63.

Zavadskas, E.K., Turskis, Z., Ustinovichius, L., Shevchenko, G., 2010. Attributes weights determining peculiarities in multiple attribute decision making methods. Eng. Econ. 66 (1), 32-43.

Zeleny, M., 1982. Multiple Criteria Decision Making. McGraw-Hill, New York. 